\title{
Looking Beyond the Surface: Use of High Resolution X-Ray Computed Tomography on Archaeobotanical Remains
}

\author{
Charlene Murphy ${ }^{\mathrm{a}}$, Dorian Q. Fuller ${ }^{\mathrm{a}, \mathrm{b}^{*}}$, Chris Stevens ${ }^{\mathrm{a}, \mathrm{c}}$, Tom Gregory ${ }^{\mathrm{a}}$, Fabio Silva ${ }^{\mathrm{d}, \mathrm{e}}$, Rita Dal \\ Martello ${ }^{\mathrm{a}}$, Jixiang Song ${ }^{\mathrm{f}}$, Andrew J. Bodey ${ }^{\mathrm{g}}$, Christoph Rau ${ }^{\mathrm{g}}$ \\ ${ }^{a}$ UCL, Institute of Archaeology, 31-34 Gordon Square, London, WC1H 0PY, United Kingdom \\ ${ }^{b}$ School of Cultural Heritage, Northwest University, Xian, 710069, China \\ 'School of Archaeology and Museology, Peking University, 100871, China \\ ${ }^{d}$ Department of Archaeology, Anthropology and Forensic Science, Bournemouth University, Fern Barrow, Poole, Dorset, BH12 5BB, United Kingdom \\ ${ }^{e}$ Faculty of Humanities and Performing Arts, University of Wales Trinity Saint David, Lampeter Campus, Ceredigion, SA48 $7 E D$, United Kingdom \\ ${ }^{f}$ Department of Archaeology, Center for Archaeological Science, Sichuan University, Chengdu, China \\ ${ }^{g}$ Diamond Light Source, Harwell Science and Innovation Campus, Oxfordshire, OX11 ODE, United Kingdom
}

\section{A RTICLE INFO}

\section{Article history:}

Received: $2^{\text {nd }}$ May 2018

Accepted: $9^{\text {th }}$ May 2019

DOI: http://dx.doi.org/ 10.24916/iansa.2019.1.1

Key words:

High-Resolution X-Ray Computed Tomography (HRXCT)

Synchrotron

morphometrics

imaging

archaeobotany

\begin{abstract}
A B S TRACT
High Resolution X-Ray Computed Tomography (HRXCT) offers a powerful 3-dimensional, nondestructive and non-invasive diagnostic tool for imaging the external and internal structures of a range of specimens of interest including archaeobotanical remains. HRXCT offers new possibilities in terms of the research questions which may be asked of fragile and valuable archaeological and specifically archaeobotanical material. This technology, although currently somewhat limited in terms of time and access to beamtimes at National Synchrotrons, requires simple, non-destructive preparation of samples and produces exciting results. Based upon two rounds of successful work, we believe that this new methodology has wider implications and utility for advancing the field of imaging, and investigating aspects of plant domestication such as internal anatomical changes.
\end{abstract}

\section{Introduction}

High Resolution X-Ray Computed Tomography (HRXCT) imaging offers a powerful 3-dimensional, non-destructive and non-invasive diagnostic tool to image the external and internal properties of a range of specimens of interest (Friis et al., 2014). HRXCT offers new possibilities in terms of the research questions which may be asked of fragile and valuable archaeological and specifically archaeobotanical material. This paper will discuss the methods and results of the successful use of HRXCT to image preserved archaeobotanical specimens of horsegram (Macrotyloma uniflorum) from different time periods ranging from the Neolithic $(4,000 \mathrm{BP})$ to modern specimens (present day) from South Asia, and additional taxa

\footnotetext{
*Corresponding author. E-mail: d.fuller@ucl.ac.uk
}

including lentil (Lens culinaris), goosefoot (Chenopodium sp.), and soybean (Glycine max).

HRXCT has grown in popularity recently as it has become more user friendly - with a broad range of disciplines employing this imaging technique, including: material sciences (Guo et al., 2017), art conservation (Cotte, 2016), conservation (Wilson et al., 2017), heritage studies (Bertrand et al., 2012), paleobotany (DeVore, Kenrick, Pigg, 2006; Friis et al., 2007; 2014; Scott et al., 2009), plant sciences (McElrone et al., 2013; Staedler et al., 2013), archaeological artefacts (Mocella et al., 2015; Bukreeva et al., 2016), archaeobotanical material (Murphy and Fuller, 2017; Zong et al., 2017), soil micromorphology (O'Donnell et al., 2007) and sedimentology (Appoloni et al., 2007).

HRXCT is a very effective method for a large range of disparate disciplines as it encompasses a wide variety of 


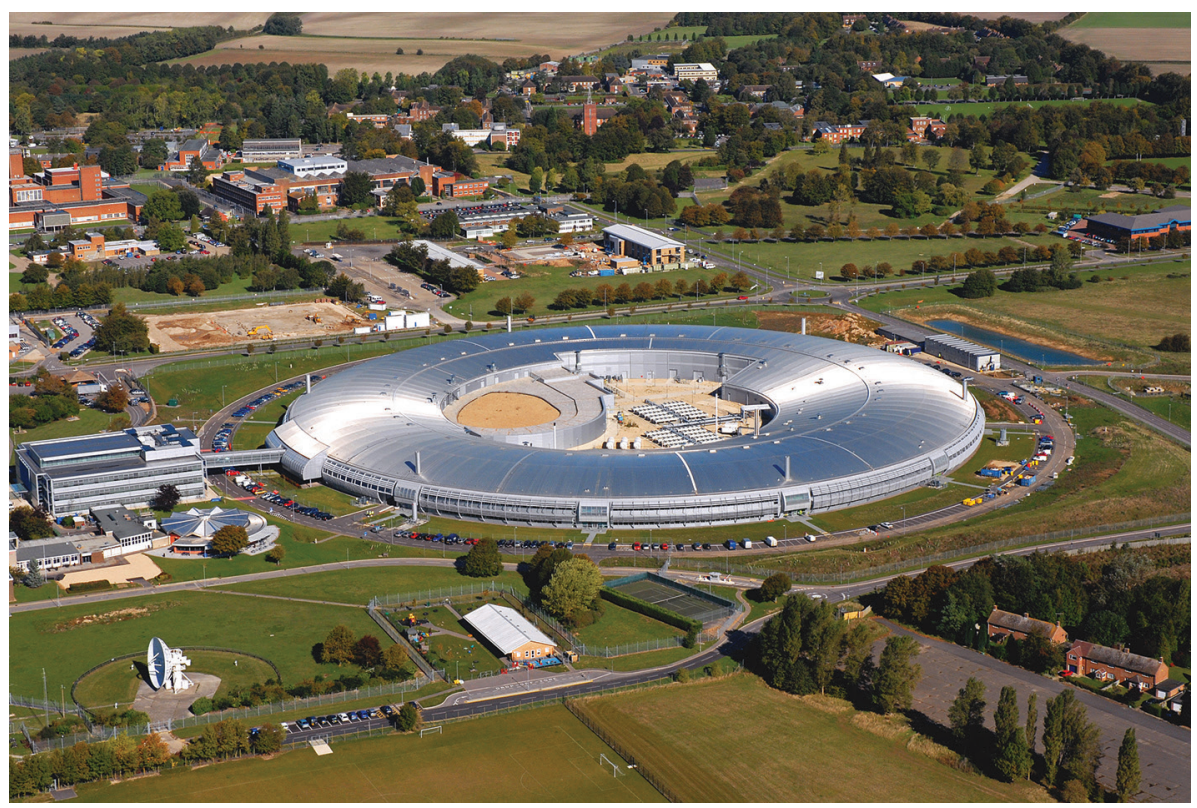

Figure 1. Aerial view of the UK Synchrotron. Image courtesy of Diamond Light Source.

advanced microscopy and imaging techniques, which can be adapted to the heterogeneous and complex structures of the materials imaged (Bertrand et al., 2012; Cnudde and Boone, 2013). Resolutions can be a little better than a micron with microtomography, and extend to nanometers with nanotomographic methods.

For our research purposes, we looked at both charred and modern seeds. We started with a $15 \mathrm{KeV}$ monochromatic beam, but progressed to using a filtered pink (polychromatic) beam for an improved high signal to noise ratio, which provided consistent and excellent image contrast for most plant applications (McElrone et al., 2013; Murphy and Fuller, 2017).

\subsection{Synchrotron technology}

HRXCT with a synchrotron employs the same principles as current medical CAT-scanning to generate three-dimensional images from two dimensional projections taken at different orientations of the specimen. HRXCT uses energies that are high enough to penetrate and study the internal structures of the specimens (Bird et al., 2008; Pantos, 2005, p.199). Synchrotron radiation is made up of extremely bright light. This type of radiation is naturally emitted by cosmic sources, but it can also be generated at synchrotron facilities such as Diamond Light Source in the UK (Figure 1) (Bertrand et al., 2012). Synchrotron radiation is produced when electrons are sped up to extremely high velocities by a linear accelerator and sent into orbit within a storage ring. Magnets, placed at various locations throughout the synchrotron storage ring, regularly bend the path of the accelerated particles as they circulate, generating synchrotron radiation (Winick, 1994; Greene, 2016) - Figure 2. The synchrotron radiation is produced with a high degree of parallelism, ranging

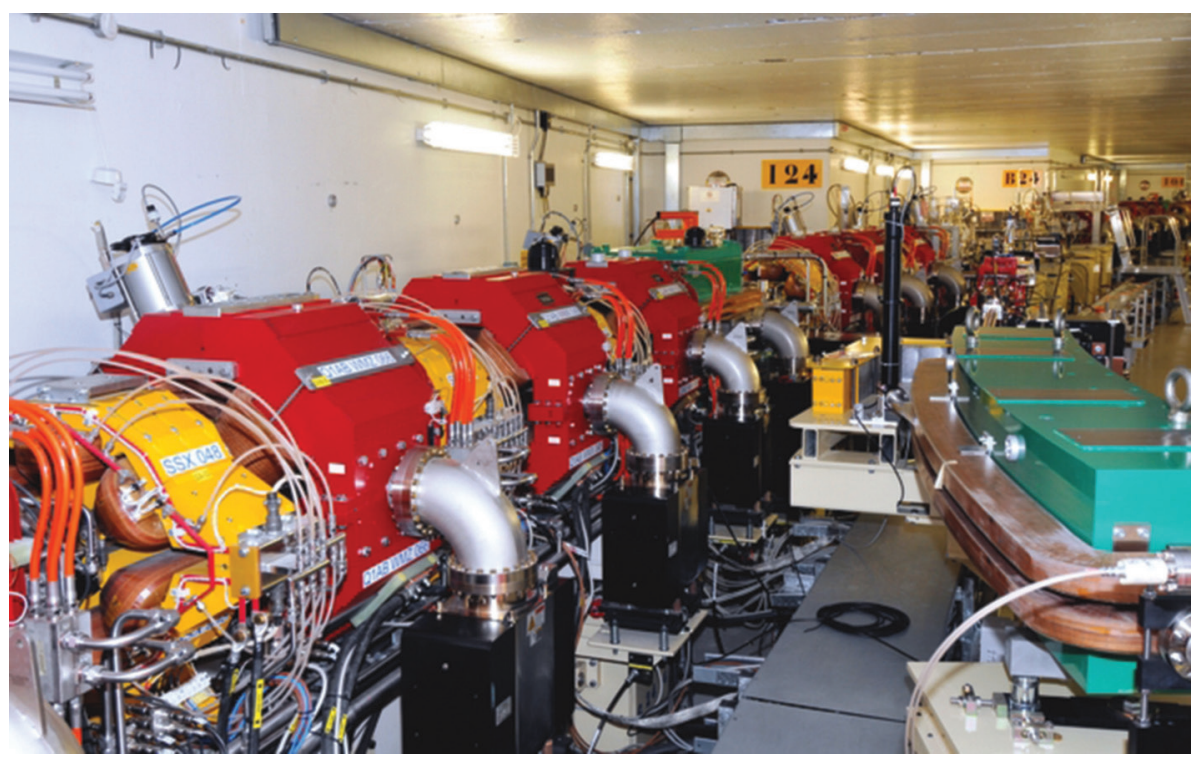

Figure 2. View of the inside of the ring at the UK Synchrotron. Image courtesy of Diamond Light Source. 
Figure 3. Walkway view of the signal-tonoise ring at the UK Synchrotron. Image courtesy of Diamond Light Source.

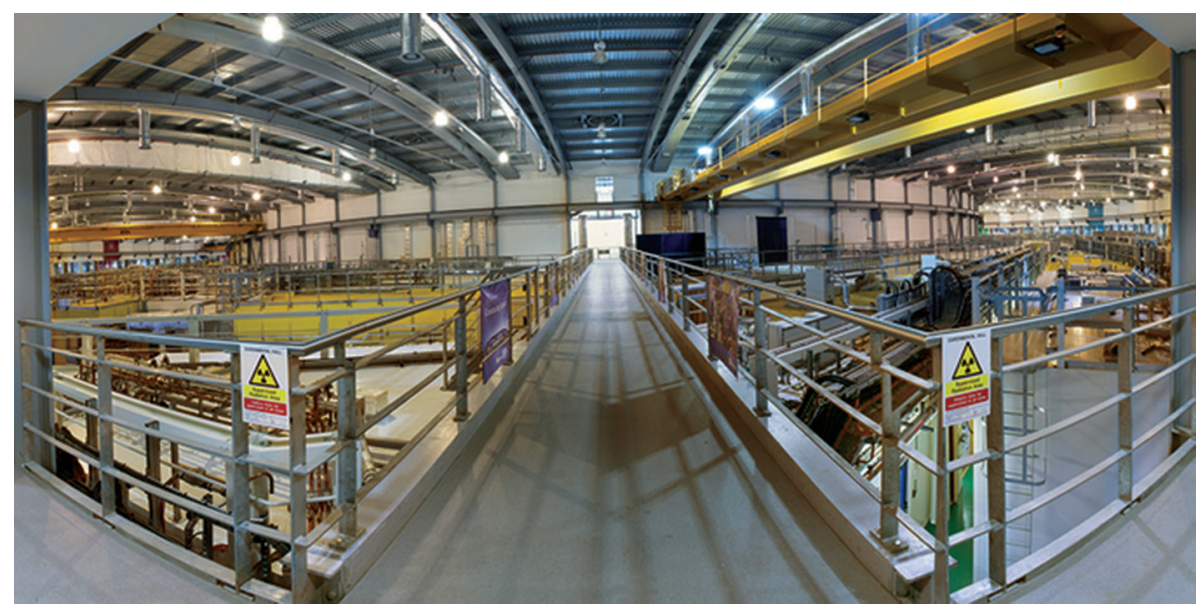

over energy levels at one extreme as low as infrared light to the so-called hard X-rays at the other (Nakai, 2005, pp.183-184). Beams generated from a synchrotron ring are four to ten orders of magnitude brighter than conventional sealed-tube X-ray emitters (Pantos, 2005, p.199; Greene, 2016). This enables faster imaging with a higher signal-tonoise ratio.

Based on the polygonal ring structure of a synchrotron facility, the synchrotron radiation is sent at long oblique angles, and transmitted down beamlines that terminate in experimental stations (Figures 1 and 2). Energy profiles and flux vary between beamlines, allowing for different types of experiments. Indeed, the advantage of synchrotronbased techniques is the brightness attained and the range of energies that allow a wide spectrum of materials to be imaged (Bertrand et al., 2012). Also, the partial coherence enabled by a long beamline such as the Diamond-Manchester Imaging Branchline I13-2 enables phase-contrast imaging; this is particularly useful for heritage, archaeological and material science fields that often possess a range of different elements within one specimen are often composed of low attenuating elements.

Figure 4. View of the Diamond-Manchester Imaging Branchline I13-2. Measuring 250 metres in length, it is the longest beamline at Diamond Light Source, the UK's Synchrotron in Oxfordshire, UK. Image courtesy of Diamond Light Source.

\subsection{History of the technique and current trends}

The potential of HRXCT as a non-destructive imaging technique for ancient and historical materials was recognized as early as the mid-1980s, with progress being made from 2000 onwards as major contributions from a narrow set of expert users expanded to include a wider range of nonspecialized users from different fields (Bertrand et al., 2012). As a result of this interdisciplinary collaboration, novel analytical strategies are becoming increasingly common as developments in advanced optics, detectors and other instrumental developments coincide (Bertrand et al., 2012). The cultural heritage and scientific archaeological communities have used, for the most part, the micro-focused spectroscopy capabilities, using a reasonably low beam divergence of synchrotron beamlines for either precise spot analyses or in raster-scanning mode to map areas of the samples being imaged (Bertrand et al., 2012). This trend has also led to improvements in the density, spatial and temporal resolution of hard X-ray tomographic microscopy. For example, recent advances in X-ray nano-imaging and nanotomography (for example, microscopy with X-ray focusing optics, and X-ray diffraction imaging techniques such as

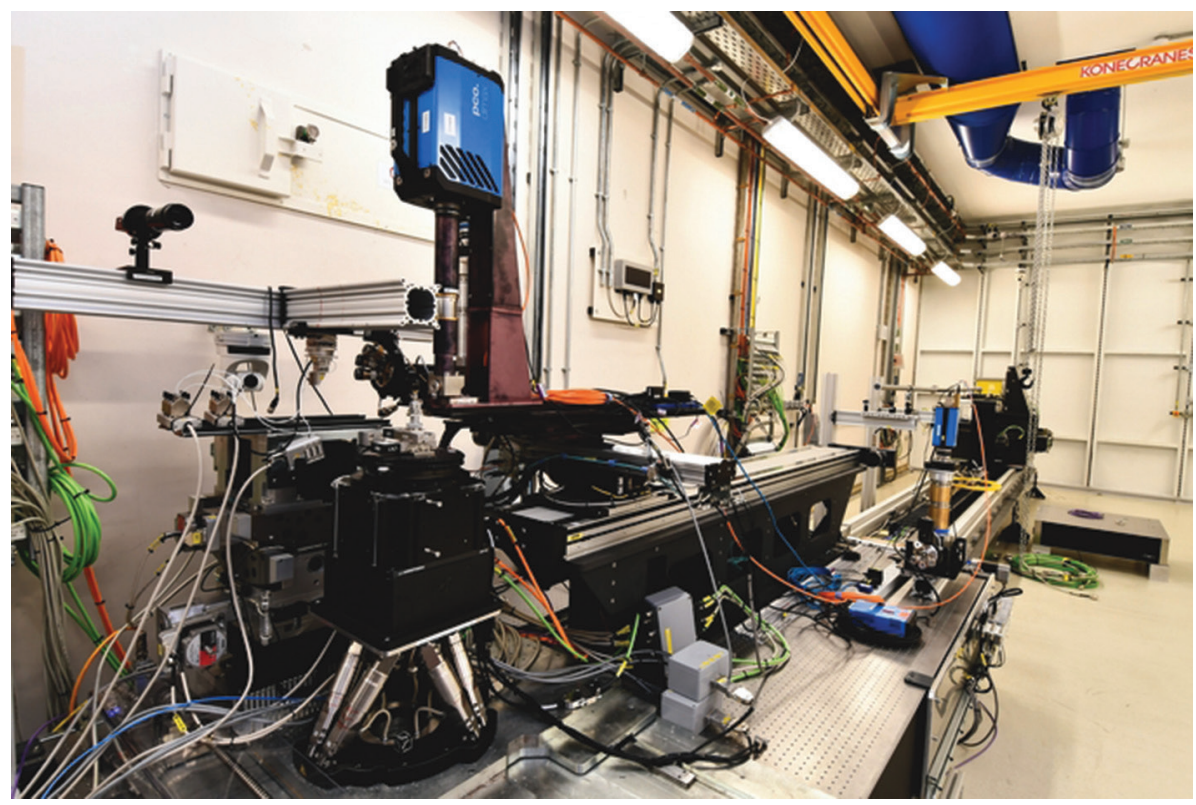



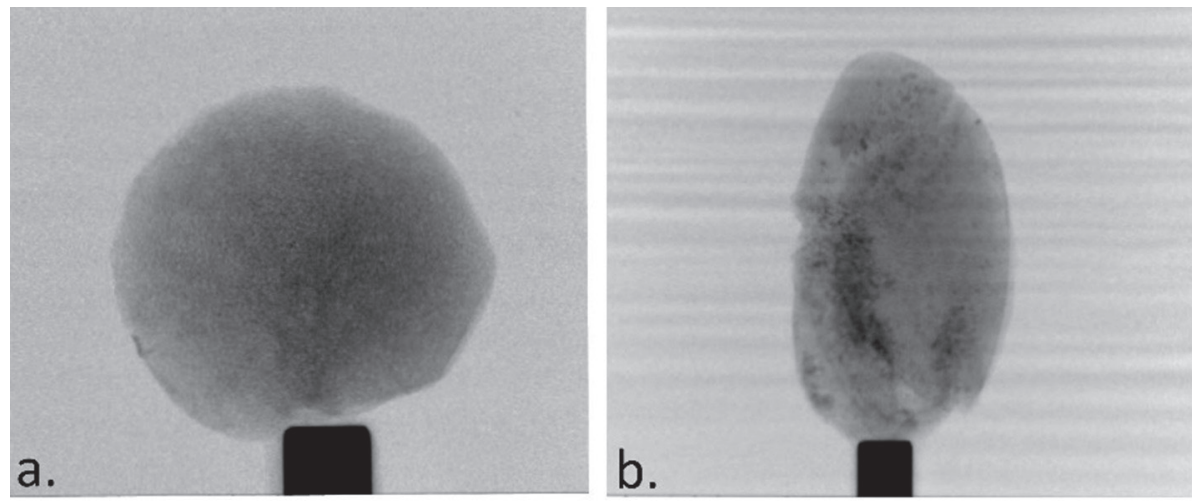

Figure 5. Images captured from Beamline I13-2 at Diamond Light Source. Charred Archaeological specimens. a) lentil b) horsegram c) soybean d) Chenopodium sp. Diameter of the CryoPin is $0.64 \mathrm{~mm}$.
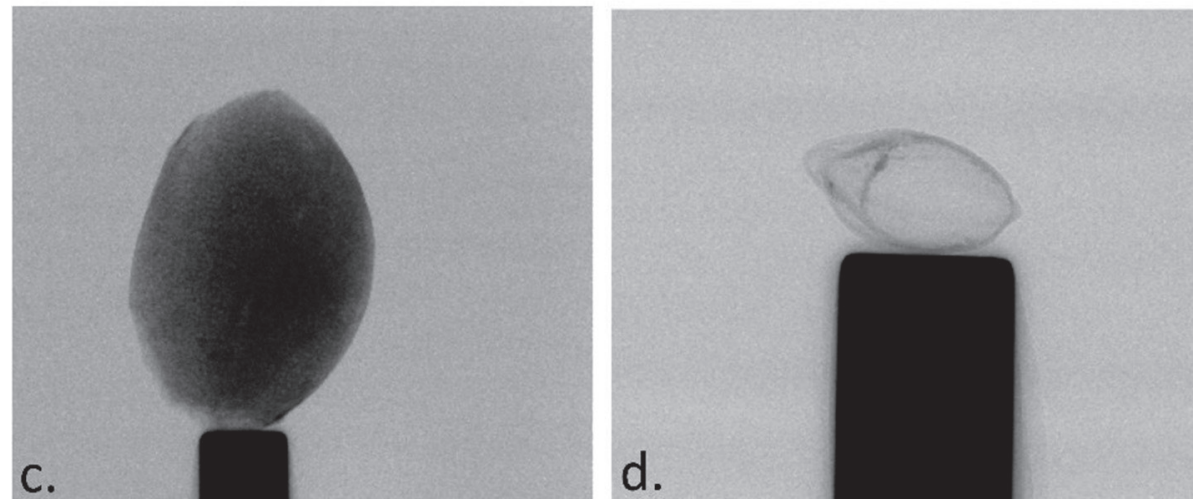

ptychography), have allowed researchers to investigate and image objects on a smaller scale.

Rapid technological and computational advances are driving the field of HRXCT towards greater usability. Based upon the increasing number of publications employing HRXCT in various disciplines that examine a range of materials, this trend is predicted to continue with HRXCT becoming a standard imaging technique in the near future (Cnudde and Boone, 2013). Digital post-processing of data for analysis and interpretation is also becoming faster and easier to perform, particularly for non-specialists (Friis et al., 2014). Software generates 3 -dimensional views and enables analyses of the specimens along with performing slices, or cross-sections, to be taken in any orientation on the same sample; a feature that is often physically impossible using traditional microscopy methods (McElrone et al., 2013). Thus, we are now able to analyze internal features and 3D volumes of specimens using dedicated software packages (Cnudde and Boone, 2013), to measure features as small as soybean pore size (Zong et al., 2017), and to digitally unravel charred papyrus scrolls from Herculaneum (Bukreeva et al., 2016), research that until recently has not been achievable.

A significant drawbank of this technique is the radiation damage that can results from the high flux of the beam (Bertrand et al., 2012). This can be minimized by various measures such that synchrotron tomography is commonly regarded as non-destructive as the samples under investigation can normally be re-analyzed using complementary analysis techniques after the synchrotron experiment (Bertrand et al., 2012). The current study experimentally tested synchrotron radiation absorption and its effect upon traditional radiocarbon dating results to test whether or not this is a nondestructive process at the atomic level. We radiocarbon dated several charred soybeans from the same two archaeological

Table 1. List of Carbonised Soybeans from the Ying Valley, China with direct AMS radiocarbon dates.

\begin{tabular}{rccccc}
\hline Site & Lab No & Taxa & Imaged & Uncalibrated C ${ }^{\mathbf{1 4}}$ date $\pm \mathbf{3 0}$ BP & Calibratedage range (95.4\%) \\
\hline Yuanqiao & 491579 & Soybean & Yes & 4400 & $3100-2910$ BC \\
Yuanqiao & 491578 & Soybean & No & 4200 & $2900-2670$ BC \\
Yuanqiao & 491580 & Soybean & No & 4360 & $3090-2900$ BC \\
Yuanqiao & 491585 & Soybean & No & 4390 & $3100-2910$ BC \\
Xiawu & 491582 & Soybean & Yes & 4100 & $2870-2500$ BC \\
Xiawu & 491586 & Soybean & Yes & 4380 & $3090-2910$ BC \\
Xiawu & 491583 & Soybean & No & 3710 & $2200-2020$ BC \\
Xiawu & 491584 & Soybean & No & 3610 & $2040-1880$ BC \\
Xiawu & 491581 & Soybean & No & 3690 & $2200-1970$ BC \\
\hline
\end{tabular}


Figure 6. The results of the outlier analysis on the model with both the untreated and irradiated samples for Xiawu. Irradiated samples are marked with $\mathrm{a} *$. The light grey distributions show the simple calibrations and the darker grey distributions show the modelled posterior estimates, including the start and end of the sequence. Also included are the posterior probabilities of the outlier analysis $(\mathrm{P})$, showing that all of the dates have a high probability of belonging to the sequence.

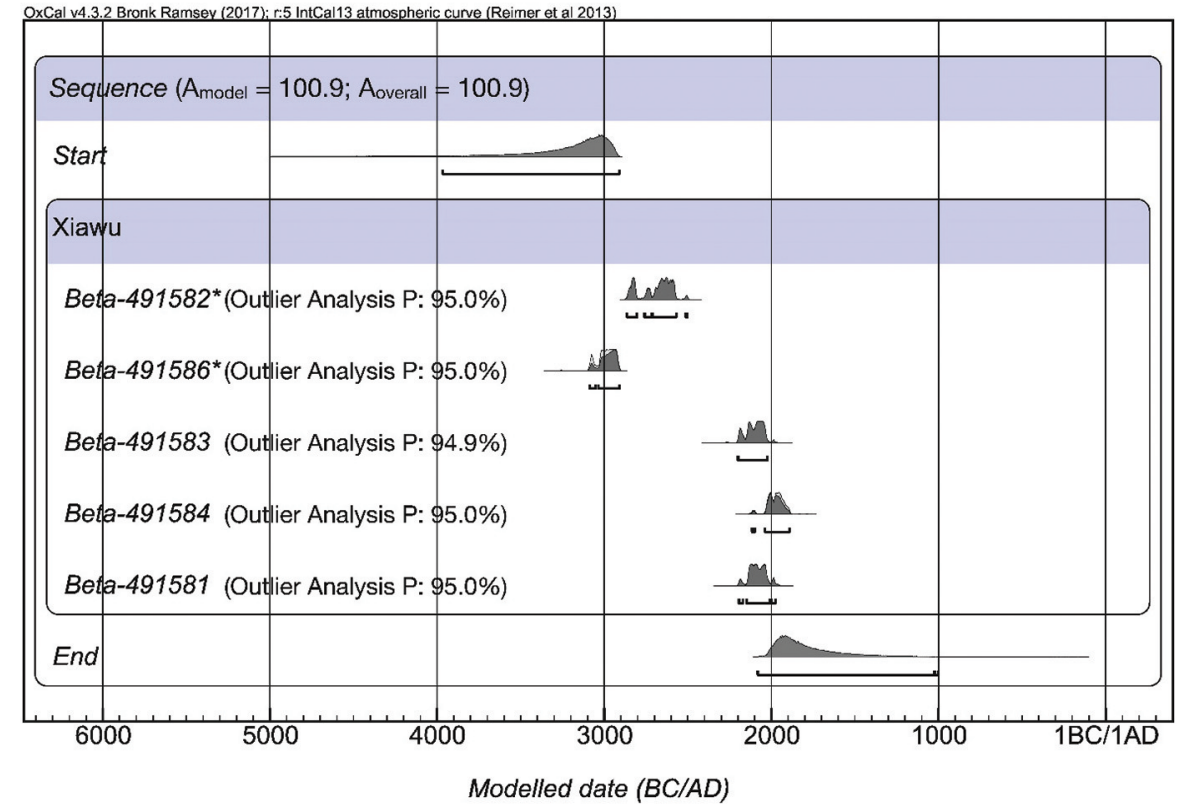

sites from the Ying Valley, China (Table 1) and found no statistically significant differences in the dating results. While damage can occur at the molecular level, this suggests that synchrotron radiation does not affect or alter specimens at an atomic level (Figure 6). The sites of Yuanqiao and Xiawu are both located in Henan Province, in the Chinese Central Plains, home of the earliest Chinese States developing in the second millenium BC. The Yuanqiao site was occupied during the mid-Yangshao Neolithic phase (4000-2500 BC), while Xiawu was occupied later, during the Longshan Neolithic phase (2500-1800 BC).

Despite the benefits and advancements of this imaging technique, a mechanical issue that can be a limitation is the physical size and shape of some objects (large and atypical objects, i.e. paintings and rocks) (Bertrand et al., 2012). Fortunately, for our study of archaeobotanical samples, they are all conveniently tiny and lie within the very small field of the beamline enabling high resolution imaging (see Methodology section).

Another practical issue that arises is limited access to National Synchrotrons. As a comparison, we ran several archaeological soybean specimens in the UCL micro-CT scanner. From our micro-CT experience we encountered roughly the same time, equipment use and computer processing issues with a slightly lower level of resolution for our archaeobotanical samples when compared with HRXCT.

Recent work on micro-CT has demonstrated burnt-out chaff temper within the core of ceramic sherds, providing reliable morphology for taxonomic identification (Barron et al., 2017). However, due to the variety in sample size, shape and composition, there are no fixed or generallyaccepted protocols which exist for micro-CT scanning to
Figure 7. The results of the outlier analysis on the model with both the untreated and irradiated samples. Yuanqiao samples are marked with $\mathrm{a} *$. The light grey distributions show the modelled posterior estimates, including the start and end of the sequence. Also included are the posterior probabilities of the outlier analysis $(\mathrm{P})$, showing that all of the dates have high probability of belonging to the sequence.

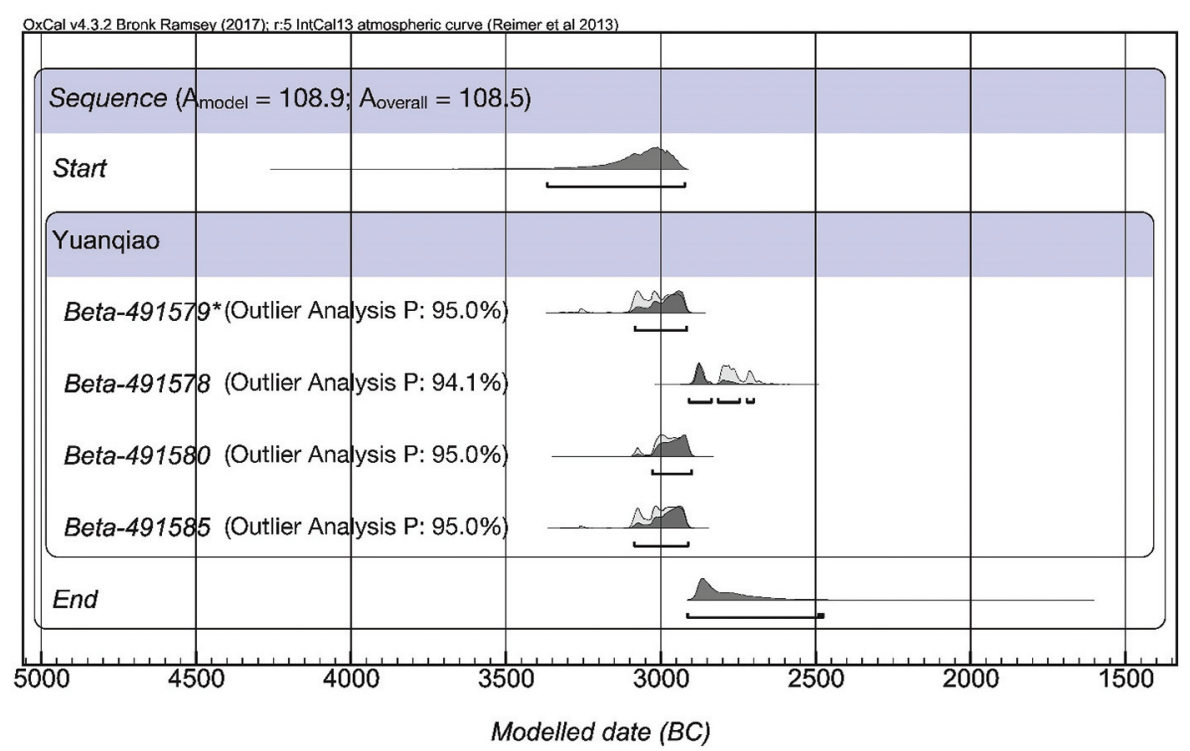


date (Cnudde and Boone, 2013). For our samples, we did find the greatest resolution possible with HRXCT to better address our research questions.

Another factor to be considered is the very large data files generated from imaging each specimen using HRXCT. The processing power needed to analyze the data after each HRXCT imaging session is currently beyond the scale of most standard university desktop computers. To help with this challenge, Diamond Light Source has developed new cluster-run reconstruction software (Savu, Atwood et al., 2015; Wadeson and Basham, 2016), and I13 has a data beamline (Bodey and Rau, 2019) for data analysis visits.

However, the use of Savu, the new tomography data processing tool developed by Diamond Light Source to compile the large image files, and its continuous improvements in functionality, is advancing quickly (http:// www.diamond.ac.uk/Science/Computing/Data-Analysis. html; savu.readthedocs.io/en/late; Basham et al., 2015; Atwood et al., 2015; Wadeson and Basham, 2016). Despite the challenges of handling and analyzing large datasets, the benefits of HRXCT to achieve 3-dimensional, highresolution images, as well as the possibilities of addressing novel research questions - particularly in a non-destructive and non-invasive manner in intact samples - makes the efforts worth it.

Another major critique of this nascent field is that until fairly recently the various heritage and archaeological disciplines have largely worked in isolation of each other and hence "the field in some respects still lacks the strong collaborative effort that was put in place in other fields of synchrotron studies such as for structural biology and nano-sciences" (Bertrand et al., 2012). However, as more interdisciplinary studies are undertaken using imaging technology on various beamlines, with the support of National Synchrotrons, this field is becoming increasingly more robust.

\subsection{Case study - seed coat thickness}

One of the shared domestication traits in many dicotyledonous crop species, notably in the bean family (Fabaceae), is a thinning of the seed coat or testa associated with changes in germination towards faster and more uniform seed germination (Butler, 1989; Gepts, 1998; Fuller and Allaby, 2009; Fuller et al., 2014). However, documenting this trait in archaeological seeds has been limited, because observations of the seed coat requires the destructive process of sectioning seeds in half and then it is difficult to achieve a perpendicular view with an SEM. Thus, there is a limited possibility to document systematically the variation in this trait across all parts of the seed coat.

To investigate this issue of seed-coat thickness as a trait of domestication, we applied for and were awarded time on the Diamond-Manchester Imaging Branchline I13-2 (Rau et al., 2011; Pesic et al., 2013) for our study of archaeobotanical material. Through HRCXT, we found that seeds and their seed coats could be imaged in their entirety, nondestructively, allowing assessment of variation in the seedcoat thickness over the entire circumference of the seed. We explored this methodology using specimens of the native Indian pulse crop horsegram (Macrotyloma uniflorum) from archaeological levels in South Indian sites Hallur, Piklihal, Sanganakallu, and Paithan, dating between 1900 BC and AD 500 , thus providing a chronological sequence that captures much of the domestication process in this crop (Murphy and Fuller, 2017).

As previously mentioned, high energy synchrotron X-rays are able to penetrate through thicker materials, providing a tool for non-destructive examination of features such as the interior structure of porous materials, as for example in soybean (Glycine max) (Zong et al., 2017). An additional benefit of our study was the ability to visualize and quantify the internal structures and preservation of both horsegram and soybean at the single cell level (Video 1). In both taxa we were surprised at the level of porosity of charred archaeological specimens (Figure 4) (Fuller and Murphy, 2016; Murphy and Fuller, 2017). We suspect that this is due to the oily composition of soybean and its response to the charring process. Whereas Zong et al. (2017) have suggested that the variation in internal structure in archaeological soybeans is due to differing proportions of oil vs protein, we suspect that the impact of charring and preservation conditions in structurally-preserved voids requires further investigation (Fuller, 2017).

\section{Methodology}

\subsection{Sample preparation and data collection}

Archaeological and modern seed specimens were individually mounted with clear nail varnish on the end of 18mm CryoPins (Molecular Dimensions Limited, MD7-410) and mounted on CryoCaps (MD7-400) at I-13-2 (Figure 3). Images were captured with the pco.4000 detector and pco. edge 5.5 detectors for the two beamlines, respectively. These were mounted on visible light microscopes of variable magnification, coupled to scintillators to convert X-rays to visible light. With the pco.edge 5.5 (which we used for pink beam imaging), $8 \times$ total magnification was sufficient to allow the imagining of whole seeds, giving a field of view of $2.1 \times 1.8 \mathrm{~mm}$ and an effective pixel size of $0.8125 \mu \mathrm{m}$ (Murphy and Fuller, 2017). Samples were continuously rotated through 180 degrees during data collection with exposure times of $70 \mathrm{~ms}$. The propagation distance was set to $20 \mathrm{~mm}$ to give a low level of phase contrast. The undulator gap was set to its minimum position of $5 \mathrm{~mm}$ and the beamline was filtered with $1.3 \mathrm{~mm}$ pyroltyic graphic, and $3.2 \mathrm{~mm}$ aluminium. For each scan "flat field" and "dark field" images were recorded. Flat field images are those images without the sample in the beam. These are often collected before and after the scan of the sample by horizontally translating the sample. Dark fields are collected by closing the X-ray shutter which measures the signal the camera produces with no X-rays (McElrone et al., 2013).

The number of projections taken during the rotation can have a significant impact on the size of the raw dataset, 
Figure 8. a) Archaeological soybean from China (YUQP2H2, Diamond Light Source 87435). b) Archaeological Chenopodium sp. from the site of Haimenkou (HMK, Diamond Light Source Lab number 87469). c) Archaeological lentil from Jarmo, Kurdistan (30/MN 14, Diamond Light Source 87467). d) Archaeological horsegram from Hallur, India with an intermediate thickness seed coat (HLR98A4, Diamond Light Source 70027). e) Archaeological horsegram from Paithan, India with a thin seed coat (PTN721, Diamond Light Source 70053).

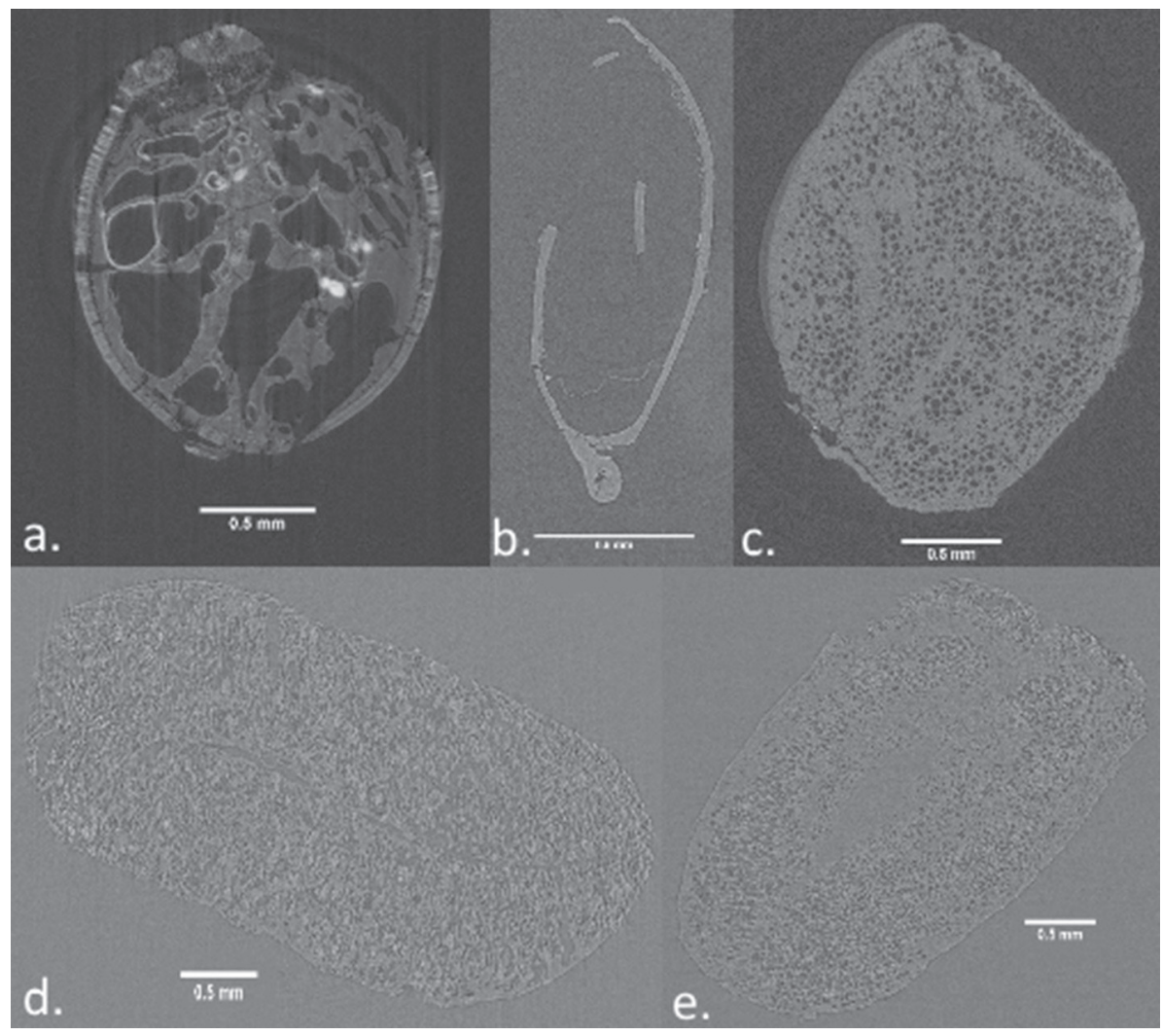

length of the scan, and final image quality, but there are diminishing returns in terms of quality which should be taken into consideration. We trialled a variety, and settled upon 6001 projection images (67 GB with dark and flatfields). In terms of data storage this may present an issue of concern to some users, although reconstructed volumes are smaller, at $51 \mathrm{~GB}$ for the pco.edge. Segmentations (classification of voxels into different components of a specimen) can be such a bottleneck that best-quality data are key to project efficiency. Thus, there is always a balance to be struck between acquisition time and image quality (Cnudde and Boone, 2013). Hence, for our own samples, we decided to have a larger dataset size and improved visual resolution for our samples as we were interested in the smaller subset of seed coat thickness. In total, the majority of our samples took 20-30 minutes to image in their entirety using the above specifications.
Tomographic reconstruction (generation of $3 \mathrm{D}$ volumes from 2D images) was computed with DAWN (Basham et al., 2015; Titarenko et al., 2010) and Savu run on the Diamond Light Source computing cluster for our first and second beamtimes, respectively. Savu is a modular pipeline which facilitates various for artefact corrections, including zinger removals, dark and flatfield correction, optical distortion corrections and ring artefact suppressions Strotton et al. 2018; Vo et al., 2018; 2015). Imaging produced between 2000 and 2672 thin section slices across each seed. Each slice was approximately $25 \mathrm{MB}$ and the combined tomographic image dataset per seed was up to 63 GB (Figure 8; Video 1). When these thin slices are added together with the raw scan images, the storage space for the basic image data for each seed was of the order of $150 \mathrm{~GB}$. This tomographic thin section can provide highly accurate measurements of seed coat thickness and the entire circumference of the slices,

Figure 9. a) Image of archaeological soybean from Baiyangcun (BYC H118, Diamond Light Source 87435). b) The same archaeological soybean segmented using SuRVoS software at Diamond Light Source. February 2018. The yellow is the testa or seedcoat, the red is the endosperm, the blue is the empty space or voids present in the interior of the seed volume, and the purple is a protein pore.

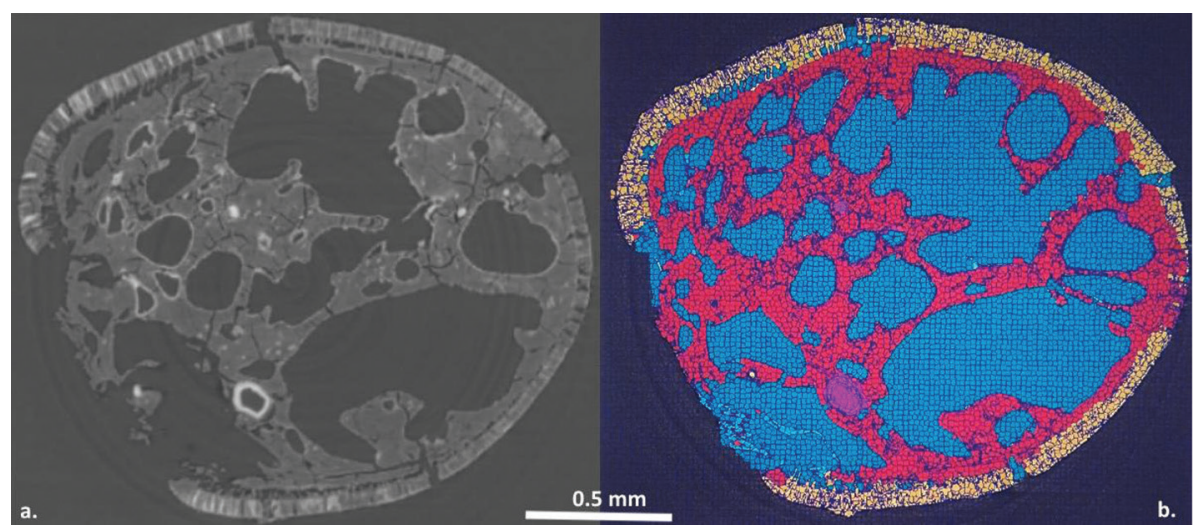


and multiple slices can be measured. In order to visualize our samples in 3D, we resampled the slices using the open source image processing package Fiji (Schindelin et al., 2012) into smaller, lower bit depth slices and visualized them in Avizo (FEI Systems, Inc., USA). Using this it is easy to visually separate the internal cellular tissue and endosperm from the seed coat but, due to similarities in densities, it is much harder to segment them using standard image segmentation algorithms. Segmentation refers to partitioning an image into separate meaningful segments; in our case, the seed coat and endosperm (see Figure 6). To do this, we used the recently-developed open-source software Super Region Volume Segmentation (SuRVoS) developed by Diamond and University of Nottingham (Luengo et al., 2017), which takes a machine learning approach to volume segmentation. Firstly, it includes a number of image filters that can reduce noise and enhance features. This preprocessing stage is important to establish a representation of the $3 \mathrm{D}$ data that aggregates voxels into supervoxels based on edges, thus lowering the total number of units to deal with, as well as enhancing the dissimilarity between the regions to be segmented. Secondly, it uses model training techniques, where the user annotates, using different coloured brushes, super-regions that correspond to the different segments. These annotated regions become part of the algorithm training dataset, which is then used to predict the full extent, in the full 3-dimensional volume, of those segments (Figure 9 Y-axis thickness in microns; Video 2). Once segmentation has been accomplished, it is possible to quantify the target structural or functional changes in texture, and morphology - including volume, length or width of individual segments (Cnudde and Boone, 2013).

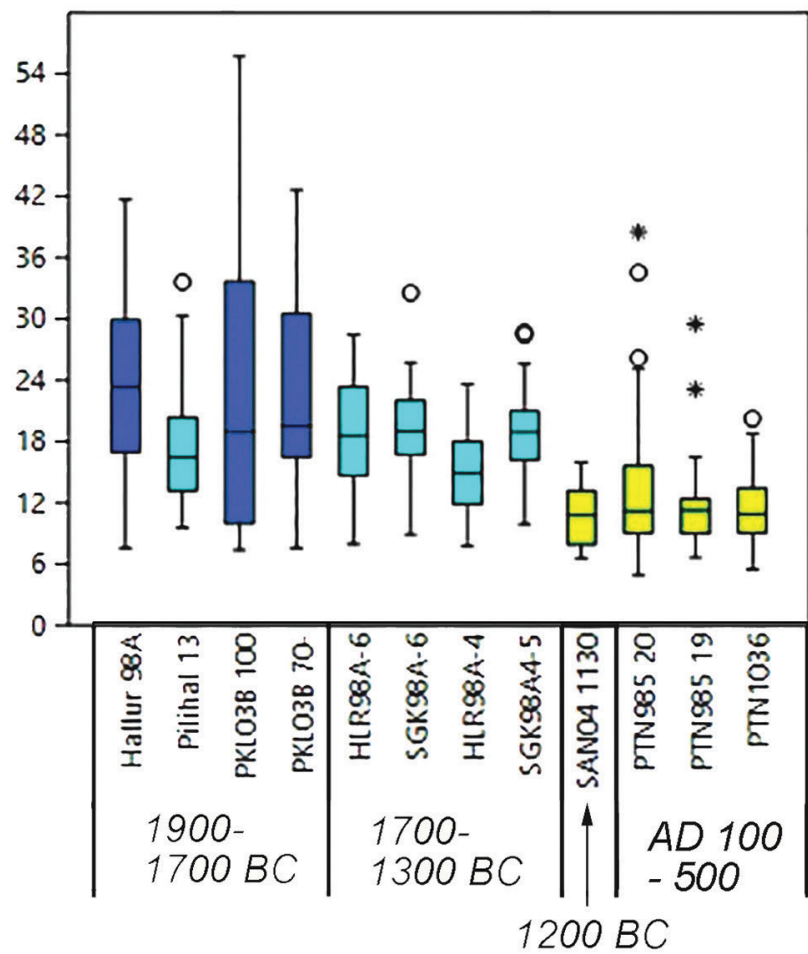

\subsection{Theories and reasoning}

As mentioned previously, seed coat thickness, particularly in pulses such as pea (Pisum sativum) (Weeden, 2007), lentil (Lens culinaris) (Ladizinsky, 1985; 1987), horsegram (Murphy and Fuller, 2017) and soybean (Lee et al., 2011), is a classic trait of domestication. The null hypothesis, that there is no change over time in seed coat thickness, was rejected. Our results support the view that, because of human intervention leading to domestication, there were genetic and phenotypic changes in which seed coat thickness decreased through time allowing germination and water penetration to occur more rapidly; an advantage in plants under cultivation (Fuller and Allaby, 2009; Butler, 1989).

\section{Results}

We rejected the null hypothesis of no change over time towards decreasing seed coat thickness in horsegram (Figures 5a; 5b; 6; 7). Instead we demonstrated that average seed coat thickness gradually became thinner over time. The results of our beamtime demonstrate that it is possible to non-destructively image archaeological seeds using HRXCT with high intensity, highly coherent synchrotron radiation with high spatial resolution with good signal to noise ratio, phase contrast, FOV (Murphy and Fuller, 2017).

These results represent the first time archaeological seed coats were measured throughout the entire circumference of the seed. Our results demonstrated empirically that there is considerable variation within individual archaeological specimens in seed coat thickness and we can confidently conclude that single spot estimates of testa thickness may

Figure 10. Boxplot of archaeological testa thickness measured on archaeological specimens of different ages (after Murphy and Fuller, 2017) Y-axis thickness is in

thick microns.

\section{intermediate}

thin 
be misleading (Figure 6). An unexpected bonus was that we were able to assess the extent of internal tissue preservation of archaeological seeds through HRCXT (Figure 5c).

\section{Discussion}

The HRXCT data generated for horsegram indicate that we were able to document evidence for morphological change in terms of average seed coat thickness over time in India. We acknowledge that some of this testa thickness variation may be due to differential shrinkage rates during preservation/charring on different parts of the same seed and post-charring damage leading to apparent thinning. This points to the need for larger numbers of testa thickness observations. Importantly, we found that there was considerable variation within individual specimens. However, between-specimen variation indicates temporal trends over time in terms of phenotypic and genetic changes in this taxon (Murphy and Fuller, 2017).

Our results for seed testa thickness in horsegram reveals a stepwise thinning over time with domestication, which would suggest that this trait is under the control of at least two or more genes (Figure 7). We therefore reject the Abbo et al. (2014, p.351) thesis that it is only the domestication traits which show "a clear domesticated-wild dimorphism [which] represents the pristine domestication episode, whereas traits showing a phenotypic continuum between wild and domesticated gene pools mostly reflect post-domestication diversification". Based upon the time depth of our samples, dating from the Neolithic to the Early Historic period in South Asia, we can be fairly confident that our archaeological samples captured much of the "domestication episode" in horsegram domestication (Murphy and Fuller, 2017). These early archaeological samples of horsegram are far too early to represent the "post-domestication" evolution of this crop in South Asia. Furthermore, this contradicts the hypothesis of "domestication before cultivation" proposed for Lens culinaris (Ladizinsky, 1987), which if true ought to apply to many or all pulse domestications. Instead seedcoat thinning evolved gradually over several centuries, up to a millennium in the case of Macrotyloma uniflorum (Murphy and Fuller, 2017).

Higher-resolution study focusing on morphometric and structural changes associated with domestication of archaeobotanical remains can be used in conjunction with, and combined with, previous traditional measurements (Fuller, Colledge, Murphy and Stevens, 2017; Fuller and Murphy, 2018). We intend to continue this successful line of investigation into seed coat thinning as a trait of domestication in other archaeological taxa from the Old World. We expect that the trends will be similar, with a decrease seen with domestication over time with gradual step-wise change.

\section{Conclusions}

HRXCT provides a useful technique for non-destructive investigations and offers new opportunities to investigate the cellular and structural properties within archaeological samples and, as this paper has demonstrated, archaeobotanical samples in particular. This non-destructive and non-invasive technique allows 3-dimensional imaging and more advanced and accurate morphometric measurements of internal features and/or structures that had hereto been impossible to visualize and quantify (Friis et al., 2014). While the study of seed coat thinning during domestication has been carried out by SEM based examination of a few point measurements on each seed (e.g. Fritz et al., 2017), synchrotron images can provide a more statistically robust assessment of withinspecimen variation in this trait and requires neither specimen destruction, nor the use of cracked or broken specimens. This technology, although currently somewhat limited in terms of time and access to beamtimes at National Synchrotrons, offers simple, non-destructive preparation of samples and exciting results. Based upon these two rounds of successful imaging results, we believe that this new methodology has wider applications and utility for investigating other aspects of plant domestication.

\section{Acknowledgements}

This research was part of the Comparative Pathways to Agriculture Project (ComPAg) funded by the European Research Council (grant 323842) and the Early Rice Project funded by the UK Natural Environment Research Council (NE/ N010957/1). Synchrotron imaging was supported by a grant of beamline time from Diamond Light Source (www. diamond.ac.uk), grant of beam time MT12082 "Drawing a thin line: Examining seedcoat thickness in relation to domestication in Macrotyloma uniflorum (horsegram)" and MT1606 "Drawing a thinner line: Examining seedcoat thickness in relation to domestication in Macrotyloma uniflorum (horsegram)". We acknowledge Diamond Light Source for time on Branchline I-13-2 and its associated data beamline (Bodey and Rau, 2017) under Proposal MT12082 and MT16061. We thank Beamline staff and its associated data beamline (Bodey and Rau, 2017) for their assistance. We would like to thank Michele Darrow, Imanol Luengo and Mark Basham for their assistance with SuRVoS software at Diamond. For access to modern reference materials we would like to thank the Royal Botanic Gardens, Kew; the London Natural History Museum herbarium, and USDA national germplasm collection.

\section{References}

ABBO, S., PINHASI VAN-OSS, R., GOPHER, A., SARANGA, Y., OFNER, I., PELEG, Z., 2014. Plant domestication versus crop evolution: a conceptual framework for cereals and grain legumes. Trends in Plant Science, 19(6), 351-60.

ATWOOD, R.C., BODEY, A.J., PRICE, S.W., BASHAM, M., DRAKOPOULOS, M., 2015. A high-throughput system for high-quality tomographic reconstruction of large datasets at Diamond Light Source. Philosophical transactions. Series A, Mathematical, physical, and engineering sciences, 373(2043). 
BARRON, A., TURNER, M., BEECHING, L., BELLWOOD, P., PIPER, P., GRUNO, E., JONES, R. OXENHAM, M., TRUNG KIEN, N.K., SENDEN, T., DENHAM, T., 2017. MicroCT Reveals Domesticated Rice (Oryza sativa) within Pottery Sherds from Early Neolithic Sites (41503265 Cal BP) in Southeast Asia. Scientific Reports, 7, 7410.

BASHAM, M., FILIK, J., WHARMBY, M.T., CHANG, P.C.Y., EL KASSABY, B., GERRING, M., AISHIMA, J., LEVIK, K., PULFORD, B.C.A., SIKHARULIDZE, I., SNEDDON, D., WEBBER, M., DHESI, S.S., MACCHEROZZI, F., SVENSSON, O., BROCKHAUSER, S., NARAY, G., ASHTON, A.W., 2015. Data Analysis WorkbeNch (DAWN). Journal of Synchrotron Radiation, 22(Pt3), 853858.

BERTRAND, L., COTTE, M., STAMPANONI, M., THOURY, M., MARONE, F., SCHODER, S., 2012. Development and trends in synchrotron studies of ancient and historical materials. Physics Reports, $519,5196$.

BERTRAND, L., VANTELON, D., PANTOS, E., 2006. Novel interface for cultural heritage at SOLEIL. Applied Physics A, 83(2), 225-228.

BODEY, A.J., RAU, C., 2017. Launch of the I13-2 data beamline at the Diamond Light Source synchrotron. Journal of Physics: Conference Series, 849(1), 012038.

BRUNO, M.C., 2006. A Morphological Approach to Documenting the Domestication of Chenopodium in the Andes. In: M.A. Zeder, D.G. Bradley, E. Emshwiller, B.D. Smith, eds. Documenting Domestication: New Genetic and Archaeological Paradigms. Berkeley and Los Angeles: University of California Press, pp. 32-45.

BUKREEVA, I., MITTONE, A., BRAVIN, A., FESTA, G., ALESSANDRELLI, M., COAN, P., FORMOSO, V., AGOSTINO, R.G., GIOCONDO, M., CIUCHI, F., FRATINI, M., MASSIMI, L., LAMARRA, A., ANDREANI, C., BARTOLINO, R., GIGLI, G., RANOCCHIA, G., CEDOLA, A., 2016. Virtual unrolling and deciphering of Herculaneum papyri by X-ray phase-contrast tomography. Scientific Reports, 6, 27227.

BUTLER, A., 1989. Cryptic anatomical characters as evidence of early cultivation in the grain legumes (pulses). In: D.R. Harris, G.C. Hillman, eds. Foraging and Farming, the Evolution of Plant Exploitation. London: Unwin Hyman Ltd., pp. 390-407.

COTTE, M., 2016. Watching works of art under the synchrotron lights to reveal their secrets. European Microscopy Congress 2016: Proceedings, $1172-1173$

CNUDDE, V., BOONE, M.N., 2013. High-resolution X-ray computed tomography in geosciences: A review of the current technology and applications. Earth-Science Reviews, 123, 1-17.

DEVORE, M., KENRICK, P., PIGG, K. 2006: Utility of high resolution X-ray computed tomography (HRXCT) for paleobotanical studies: an example using London Clay fruits and seeds. American Journal of Botany, 93, 1848-1851.

FRITZ, G.J., BRUNO, M.C., LANGLIE, B.S., SMITH, B.D., KISTLER, L., 2017. Cultigen Chenopods in the Americas: A Hemispherical Perspective In: M.P. Sayre, M.C. Bruno, eds. Social Perspectives on Ancient Lives from Paleoethnobotanical Data. Cham: Springer International Publishing AG, pp. 55-75.

FULLER, D.Q, 2002. Fifty Years of Archaeobotanical Studies in India: Laying a Solid Foundation. In: S. Settar, R. Korisettar, eds. Indian Archaeology in Retrospect, vol. III of Archaeology and Interactive Disciplines. Manohar, New Dehli: Publications of the Indian Council for Historical Research, pp.247-364.

FULLER, D.Q, 2011. Finding Plant Domestication in the Indian Subcontinent. Current Anthropology, 52, S347-S362.

FULLER, D.Q, 2017. Using big machines to look at the finer aspects of seeds. The Archaeobotanist Blogspot, 21 November 2017. http:// archaeobotanist.blogspot.co.uk/search?q=horsegram

FULLER, D.Q, HARVEY, E.L., 2006. The archaeobotany of Indian pulses: identification, processing and evidence for cultivation. Environmental Archaeology, 11, 219-246.

FULLER, D.Q, MURPHY, C., 2014. Overlooked but not forgotten: India as a center for agricultural domestication. General Anthropology, 21, 1-8.

FULLER, D.Q, MURPHY, C., 2016. UCL, Institute of Archaeology Report to Diamond Light Source for session MT12082 on Beamline 113-2. Drawing a thin line: Examining seedcoat thickness in relation to domestication in Macrotyloma uniflorum (Horsegram).

FULLER, D.Q, MURPHY, C., 2018. The origins and early dispersal of horsegram (Macrotyloma uniflorum), a major crop of ancient India.
Genetic Resources and Crop Evolution, 65(1), 285-305.

FULLER, D.Q, DENHAM, T., ARROYO-KALIN, M., LUCAS, L., STEVENS, C., QIN, L., ALLABY, R.G., PURUGGANAN, M.D., 2014. Convergent evolution and parallelism in plant domestication revealed by an expanding archaeological record. Proceedings of the National Academy of Sciences of the United States of America, 111, 6147-6152.

FULLER, D.Q, COLLEDGE, S., MURPHY, C., STEVENS, C.J., 2017. Sizing up cereal variation: patterns in grain evolution revealed in chronological and geographical comparisons. In: J.F. Eraso, J.A.M. Alustiza, A.A. Valbuena, M.G. De, eds. Miscelnea en homenaje a Lydia Zapata Pea (1965-2015). Bilbao: Servicio Editorial Universidad Del Pas Vasco, 131-149.

FRIIS, E.M., MARONE, F., PEDERSEN, K.R., CRANE, P.R., STAMPANONI, M., 2014. Three-dimensional visualization of fossil flowers, fruits, seeds, and other plant remains using synchrotron radiation X-ray tomographic microscopy (SRXTM): new insights into Cretaceous plant diversity. Journal of Paleontology, 88(4), 684-701.

GEPTS, P., 1998. Origins and Evolution of Common Bean: Past Events and Recent Trends. Hort. Science, 33(7), 1124-1130.

GREENE, A.F., 2016. Synchrotron Radiation. In: A. Hunt, ed. The Oxford Handbook of Archaeological Ceramic Analysis. Online Publication. 10.1093/oxfordhb/9780199681532.013.25.

GUO, E., ZENG, G., KAZANTSEV, D., ROCKETT, P., BENT, J., KIRKLAND, M., VAN DALEN, G., EASTWOOD, D.S., STJOHN, D., LEE, P.D., 2017. Synchrotron X-ray tomographic quantification of microstructural evolution of ice cream- a multi-phase soft solid. RSC Advances, 7, 15561-15573.

HOOKER, J., 1879. The Flora of British India, vol. 2. London: L. Reeve $\& \mathrm{Co}$

LADIZINSKY, G., 1987. Pulse domestication before cultivation. Economic Botany, 41, 60-65.

LADIZINSKY, G., 1985. The genetics of hard seed coat in the genus Lens. Euphytica, 34, 539-543.

LUENGO, I., DARROW, M.C., SPINK, M.C., SUN, Y., DAI, W., HE, C.Y., CHIU, W., PRIDMORE, T., ASHTON, A.W., DUKE, E.M.H, BASHAM, M., FRENCH, A.P., 2017. SuRVoS: Super-Region Volume Segmentation workbench. Journal of Structural Biology, 198(1), 43-53.

MCELRONE, A.J., CHOAT, B., PARKINSON, D.Y., MACDOWELL, A., BRODERSEN, C.R., 2013. Using High Resolution Computed Tomography to Visualize the Three Dimensional Structure and Function of Plant Vasculature. Journal of Visualised Experiments, 74, 50162.

Mocella, V., BRUN, E., FERrero, C., Delattre, D., 2015. Revealing letters in rolled Herculaneum papyri by X-ray phase-contrast imaging. Nature Communications, 6, 5895.

MOLES, A.T., ACKERLY, D.D., TWEDDLE, J.C., DICKIE, J.B., SMITH, R., LEISHMAN, M.R., MAYFIELD, M.M., PITMAN, A., WOOD, J.T., WESTOBY, M., 2007. Global patterns in seed size. Global Ecology and Biogeography, 16, 109-116.

MURPHY, C., FULLER, D.Q., 2017. Seed coat thinning during horsegram (Macrotyloma uniflorum) domestication documented through synchrotron tomography of archaeological seeds. Scientific Reports, 7, 5369.

MURPHY, C., FULLER, D.Q, 2016. The Transition to Agricultural Production in India: South Asian Entanglements of Domestication. In: G.R. Schug, S.R. Walimbe, eds. A Companion to South Asia in the Past. Hoboken: John Wiley \& Sons, Inc., pp.344-357.

PEŚIĆ, Z., DE FANIS, A., WAGNER, U. and RAU, C. 2013. Experimental stations at I13 beamline at Diamond Light Source. Journal of Physics: Conference Series, 425, 182003.

PURUGGANAN, M., FULLER, D.Q, 2011. Archaeological data reveal slow rates of evolution during plant Domestication. Evolution, 65, 171183.

RAMSEY, C.B. 2009a. Bayesian analysis of radiocarbon dates. Radiocarbon, 51(1), 337-360.

RAMSEY, C.B. 2009b Dealing with Outliers and O sets in Radiocarbon Dating. Radiocarbon, 51(3), 1023-1045.

RAU, C., WAGNER, U., PESIC, Z., DE FANIS, A., 2011. Coherent imaging at the Diamond beamline I13. Physica status solid (a), 208(11), $2522-2525$

SCHINDELIN, J., ARGANDA-CARRERAS, I., FRISE, E., KAYNIG, V., LONGAIR, M., PIETZSCH, T., PREIBISCH, S., RUEDEN, C., SAALFELD, S., SCHMID, B., TINEVEZ, J.-Y., WHITE, D.J., 
HARTENSTEIN, V., ELICEIRI, K., TOMANCAK, P., CARDONA, A., 2012. Fiji: an open-source platform for biological-image analysis. Nature methods, 9(7), 676-682, PMID 22743772.

SCOTT, A.C., 2010. Charcoal Recognition, Taphonomy and Uses in Palaeoenvironmental Analysis. Palaeogeography, Palaeoclimatology, Palaeoecology, 291(1-2), 11-39.

SEARS, D.W.G., SEARS, H., EBEL, D.S., WALLACE, S., FRIEDRICH, J., 2016. X-Ray Computed Tomography Imaging: A Not-so-Nondestructive Technique. Meteoritics and Planetary Science, 51(4), 833-838.

STAEDLER, Y.M., MASSON, D., SCHONENBERGER, J., 2013. Plant Tissues in 3D via X-Ray Tomography: Simple Contrasting Methods Allow High Resolution Imaging. PLoS ONE, 10.1371/journal.pone.0075295.

STROTTON, M.C., BODEY, A.J., WANELIK, K., DARROW, M.C., MEDINA, E., HOBBS, C., RAU, C. and BRADBURY, E.J., 2018. Optimising complementray soft tissue synchrotron X-ray microtomography for reversibly-stained central nervous system samples. Scientific Reports, 8(1), 12017.

TITARENKO, V., BRADLEY, R., MARTIN, C., WITHERS, P. J. and TITARENKO, S. 2010. Regularization methods for inverse problems in X-ray tomography. SPIE Optical Engineering + Applications. International Society for Optics and Photonics, 78040Z-78040Z-10.

VO, N.T., ATWOOD, R.C. and DRAKOPOULOS, M., 2018. Superior techniques for eliminating ring artifacts in x-ray microtomography. Optics express, 26(22), 28396-28412.

VO, N.T., ATWOOD, R.C., DRAKOPOULOS, M. 2015. Radial lens distortion correction with sub-pixel accuracy for X-ray microtomography. Optics express 23, 32859-32868 (DOI: 10.1364/OE.23.032859).

WADESON, N., BASHAM, M., 2016. Sauv: A Phython-based, MPI Frame-work for Simultaneous Processing of Multiple, N-dimensional,
Large Tomography Datasets. arXiv preprint arXiv:1610.08015.

WEEDEN, N., 2007. Genetic Changes Accompanying the Domestication of Pisum sativum: Is there a Common Genetic Basis to the Domestication Syndrome for Legumes? Annuals of Botany, 100(5), 1017-1025.

WILSON, P., WILLIAMS, M.A., WARNETT, J.M., ATTRIDGE, A., KETCHUM, H., HAY, J., SMITH, M.P., 2017. Utilizing X-Ray Computed Tomography for heritage conservation: the case of Megalosaurus bucklandii. In: I2MTC 2017 IEEE International Instrumentation and Measurement Technology Conference, Torino, Italy, 22-25 May 2017. Published in IEEE International Instrumentation and Measurement Technology Conference (12MTC).

ZONG, Y., YAO, S., CRAWFORD, G.W., FANG, H., LANG, J., FAN, J., SUN, Z., LIU, Y., ZHANG, J., DUAN, X., ZHOU, G., XIAO, T., LUAN, F., WANG, Q., CHEN, X., JIANG, H., 2017. Selection for Oil Content During Soybean Domestication Revealed by X-Ray Tomography of Ancient Beans. Scientific Reports, 7, 43595.

\section{Websites}

http://www.diamond.ac.uk/Beamlines/Materials/I13.html [Accessed 1/09/2017] http://www.diamond.ac.uk/Beamlines/Materials/Techniques/XTT.html [Accessed 1/09/2017]

http://www.diamond.ac.uk/Science/Computing/Data-Analysis.html [Accessed 09/10/2017]

https://diamondlightsource.github.io/SuRVoS/ [Accessed 17/01/2018] savu.readthedocs.io/en/latest/about/ [Accessed 13/03/2018] 


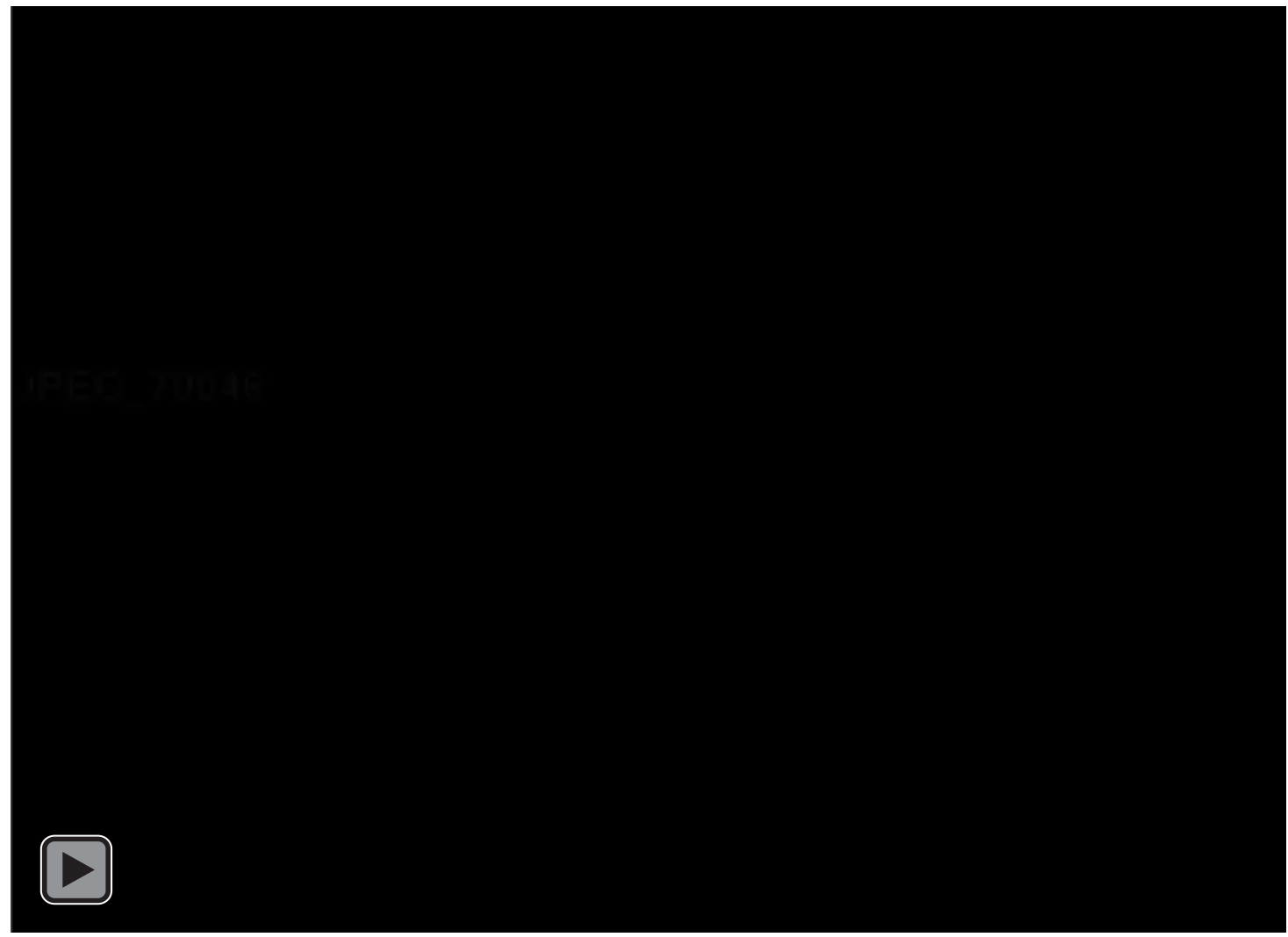

Video 1. Compiled video of archaeological horsegram imaged during the 2015 session at Diamond Light Source.

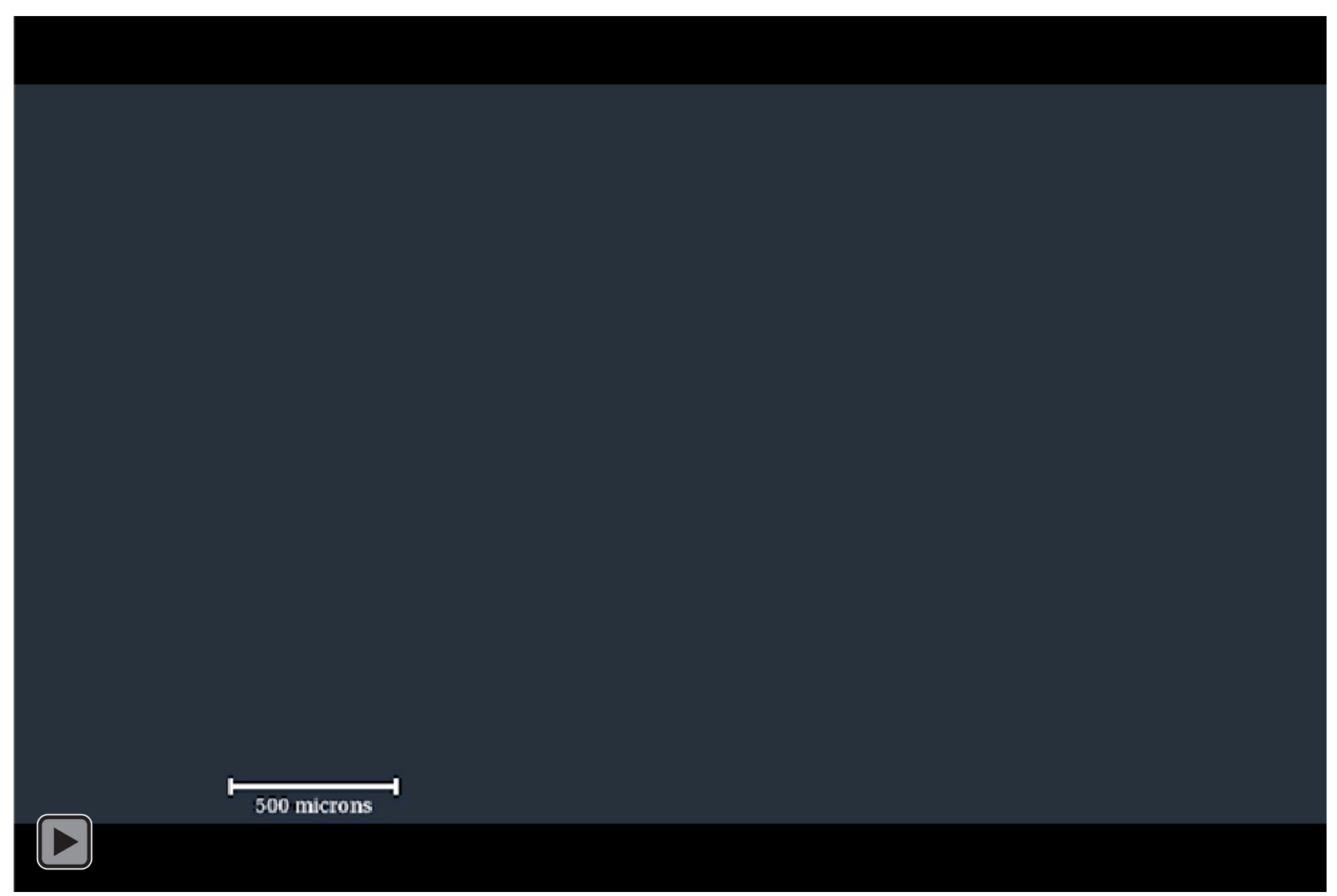

Video 2. 3-dimensional render of archaeological soybean from China dating to the Neolithic. Imaged during the 2017 session at Diamond Light Source. 